\title{
Correction: Induction of labour versus expectant monitoring for gestational hypertension or mild pre-eclampsia between 34 and 37 weeks' gestation (HYPITAT-II): a multicentre, open-label randomised controlled trial
}

\author{
Kim Broekhuijsen ${ }^{1 *}$, Josje Langenveld ${ }^{2}$, Gert-Jan van Baaren ${ }^{3}$, Mariëlle G van Pampus ${ }^{4}$, Anton H van Kaam³ \\ Henk Groen ${ }^{5}$, Martina Porath ${ }^{6}$, Maureen TM Franssen ${ }^{1}$, Ben W Mol${ }^{3}$ and HYPITAT-II study group
}

The earliest draft versions of the protocol for our study described the composite adverse maternal outcome as one or more of progression to severe disease, pulmonary edema, thrombo-embolic disease, HELLP syndrome, eclampsia, placental abruption or maternal death. However, there is ongoing debate as to whether progression to severe disease should be considered an adverse maternal outcome [1,2]. Therefore, after obtaining funding which enabled us to increase our sample size to the current sample size of 680 , we decided to study a composite adverse maternal outcome excluding progression to severe disease. These changes were incorporated in the protocol as submitted to and approved by the instutional review board;" the current protocol is available from our website (http://www.studies-obsgyn.nl/hypitat2/ page.asp?page_id=642). Unfortunately, the change to the maternal outcome definition was not incorporated into the published protocol, which incorrectly includes progression to severe disease in the composite adverse maternal outcome [3].

We also discovered minor differences between the published protocol and the IRB approved protocol. The definition for neonatal morbidity should have contained meconium aspiration syndrome, pneumothorax and/or pneumomediastinum, periventricular leucomalacia, convulsions and other neurological abnormalities. Finally, low 5-minute Apgar score should have been defined as below 7 (as opposed to below 3), and low umbilical artery $\mathrm{pH}$ as below 7.05 (as opposed to below 7.0).

\footnotetext{
* Correspondence: k.broekhuijsen@gmail.com

'Department of Obstetrics and Gynecology, University of Groningen,

University Medical Center Groningen, Groningen, The Netherlands

Full list of author information is available at the end of the article
}

These discrepancies were discovered and the correction submitted for publication during recruitment.

* Medical Ethics Committee, Academic Medical Centre, Amsterdam, the Netherlands (ref. 2008/244).

\section{Author details}

'Department of Obstetrics and Gynecology, University of Groningen, University Medical Center Groningen, Groningen, The Netherlands. ${ }^{2}$ Department of Obstetrics and Gynecology, Atrium Medical Center, Heerlen, The Netherlands. ${ }^{3}$ Department of Obstetrics and Gynecology, Academic Medical Center, Amsterdam, The Netherlands. ${ }^{4}$ Department Obstetrics and Gynecology, Onze Lieve Vrouwe Gasthuis, Amsterdam, The Netherlands. ${ }^{5}$ Department of Epidemiology, University of Groningen, University Medical Center Groningen, Groningen, The Netherlands. ${ }^{6}$ Department of Obstetrics and Gynecology, Maxima Medical Center, Veldhoven, The Netherlands.

Received: 24 January 2013 Accepted: 6 December 2013

Published: 23 December 2013

\section{References}

1. Koopmans CM, Bijlenga D, Groen H, Vijgen SM, Aarnoudse JG, Bekedam DJ, HYPITAT study group, et al: Induction of labour versus expectant monitoring for gestational hypertension or mild pre-eclampsia after 36 weeks' gestation (HYPITAT): a multicentre, open-label randomised controlled trial. Lancet 2009, 374:979-988.

2. Bewley S, Shennan A: Hypitat and the fallacy of pregnancy interruption. Lancet 2010, 375(9709):119.

3. Langenveld J, Broekhuijsen K, van Baaren G, van Pampus MG, van Kaam AH, Groen H, Porath M, Mol BW, HYPITAT-II study group: Induction of labour versus expectant monitoring for gestational hypertension or mild preeclampsia between 34 and 37 weeks' gestation (HYPITAT-II): a multicentre, open-label randomised controlled trial. BMC Pregnancy Childbirth 2011, 11:50.

\section{doi:10.1186/1471-2393-13-232}

Cite this article as: Broekhuijsen et al:: Correction: Induction of labour versus expectant monitoring for gestational hypertension or mild pre-eclampsia between 34 and 37 weeks' gestation (HYPITAT-II): a multicentre, open-label randomised controlled trial. BMC Pregnancy and Childbirth 2013 13:232 